\title{
Adaptive Control of the WEDM Process Using the Fuzzy Control Strategy
}

M.T. Yan, Mechanical Industry Research Laboratories, Hsinchu, Taiwan

Y.S. Liao, National Taiwan University, Taipei, Taiwan

\begin{abstract}
The proportion of abnormal sparks (abnormal ratio) and the sparking frequency are employed to monitor and evaluate the gap condition of the wire electrical discharge machining (WEDM) process on-line. The relationships are investigated between these two sensing parameters and wire breaking phenomenon, metal removal rate (MRR), and surface roughness of the machined part under various machining conditions. Based on the results, an adaptive control optimization (ACO) system is developed. Fuzzy rules based on operator experience and expert knowledge are constructed, and a multivariable and three-region fuzzy controller is designed and implemented. By regulating the servo feed and the pulse off-time in real time, the abnormal ratio is controlled at a predetermined value for optimum and stable machining, while at the same time the sparking frequency is kept under a critical value for wire rupture prevention. Experimental results demonstrate that the developed control system results in very satisfactory performance.
\end{abstract}

Keywords: WEDM, Wire Breaking, Adaptive Control, Fuzzy Controller

\section{Introduction}

Since the introduction of $\mathrm{CNC}$ wire electrical discharge machining (WEDM) machines to the market in the 1970s, the technology of servo feed control has been accelerated because of the need for improvements in machining speed and part quality. Conventionally, the servo feed control of EDM or WEDM processes is accomplished by taking the average gap voltage as the only feedback signal. The difference between this signal and a predetermined servo reference voltage is used to adjust the gap distance by driving the servo mechanism of the machine. Since the average gap voltage does not provide detailed information about normal discharge, arc discharge, and short circuit, the gap condition is not retrieved comprehensively. As a result, the control system may become unstable. Many adaptive control systems for EDM or WEDM processes have been developed over the years. They are categorized into two types. For the first type of system, the gap condition is controlled by employing simple algorithms based on the constructed data and knowledge base. ${ }^{1-5}$ This type of control system can be applied to a wide range of machining conditions; however, a large memory space is needed to store experimental data. Also, because of the simple control strategies the systems cannot respond promptly to gap condition when there is unexpected disturbance during the machining process. The second type of adaptive control system is developed by applying modern digital control technologies such as stochastic control, model reference adaptive control, and fuzzy control strategy. The stochastic and adaptive control systems have quick response during machining because the controller's parameters can be regulated according to on-line identification of the EDM process. ${ }^{6-10}$ However, the material removal process of WEDM or EDM changes drastically with machining conditions. Finding an approximated mathematical model for the complex process is difficult and time consuming. In addition, the transient behavior of this type of system is hardly predictable, and machining stability is not guaranteed. Recently, fuzzy control systems for the EDM process have also been developed. ${ }^{11,12}$ But the control targets for this type of control system are not closely related to MRR, surface quality of the machined part, and so on. Thus, it is difficult for these control systems to specify the reference value of the control output.

In addition to these two types of adaptive control systems, expert systems were also developed for control of the WEDM process to improve machining speed without increasing the risk of wire breakage. ${ }^{13}$ However, due to the large computation task resulting from the slow learning speed, an expert system does not work satisfactorily for on-line control of WEDM.

The metal removal process of WEDM involves complex, stochastic, and time-varying characteristics. Moreover, the process features change drastically with machining parameters. All these factors make the process very difficult, if not impossible, to be 
described by a mathematical model. Hence, classical control strategy and modern control technology based on a well-defined (either deterministically or stochastically) mathematical model are not applicable. In addition, due to the stochastic nature of the process, even a highly skilled operator is unable to achieve optimal performance and avoid wire breakage as machining progresses. The objective of this paper is to develop a controller that not only can cope with the WEDM process, it can also simulate operator and expert experience so as to maintain optimal performance without the risk of wire rupture.

Fuzzy control theory can easily capture the approximate and qualitative aspects of human knowledge and can perform reasoning as well as simulate human intelligence for controlling a complicated process. The control strategy has been successfully applied to various industrial processes where mathematical models are ill-defined. ${ }^{\mathbf{1 4 - 1 6}}$ In this paper, a monitoring and adaptive control optimization (ACO) system based on the fuzzy logic strategy for WEDM is developed. Two sensing parameters are employed to monitor the gap condition by means of a computer-aided sparking frequency monitoring system. These two parameters are controlled at a desired state by regulating the feed and pulse off-time in real time for optimum, stable machining and wire rupture prevention. Experiments demonstrate that stable and high-speed machining can be obtained with the developed system.

\section{Experimental Setup and In-Process Evaluation of WEDM \\ Sparking Frequency Monitoring and Control System}

A prototype WEDM machine, developed by the Mechanical Industry Research Laboratories (MIRL) of the Industrial Technology Research Institute (ITRI) in Taiwan, is employed. This machine consists of a power supply system, a dielectric regeneration system, a computer numerical control system, a five-axis motion system, and a flushing device. The power unit consists of a low-power circuit and a high-power circuit. The low-power circuit leads the gap to discharge by supplying a low DC voltage of $110 \mathrm{~V}$, and the high-power circuit contributes to metal removal by supplying $220 \mathrm{~V}$ voltage. Gap status is monitored and discriminated by detecting the ignition delay time and level of gap voltage. A nor- mal discharge is determined when the instantaneous gap voltage is higher than a predetermined reference voltage after a pre-set delay time. On the contrary, an abnormal discharge (an arc discharge or short circuit) is determined when the detected voltage is lower than the reference voltage. ${ }^{17}$ Discharge current of this power system has a triangular waveform with a constant slope of $380 \mathrm{~A} / \mu \mathrm{s}$. Figure 1 shows the typical gap voltages (top plot) and their associated current waveforms (bottom plot) of normal discharge, arc discharge, and short circuit from this machine. The adjustable parameters of this machine include pulse on-time, pulse off-time, feedrate override, wire speed, and wire tension. Their working ranges are listed in Table 1. The maximum machining speed that can be achieved under a suitable machining condition by a skilled operator is about $120 \mathrm{~mm}^{2} / \mathrm{min}$.

A network-type sparking frequency monitoring and control system is developed as illustrated in Figure 2. By using this system, the total number of sparks $(N t)$,

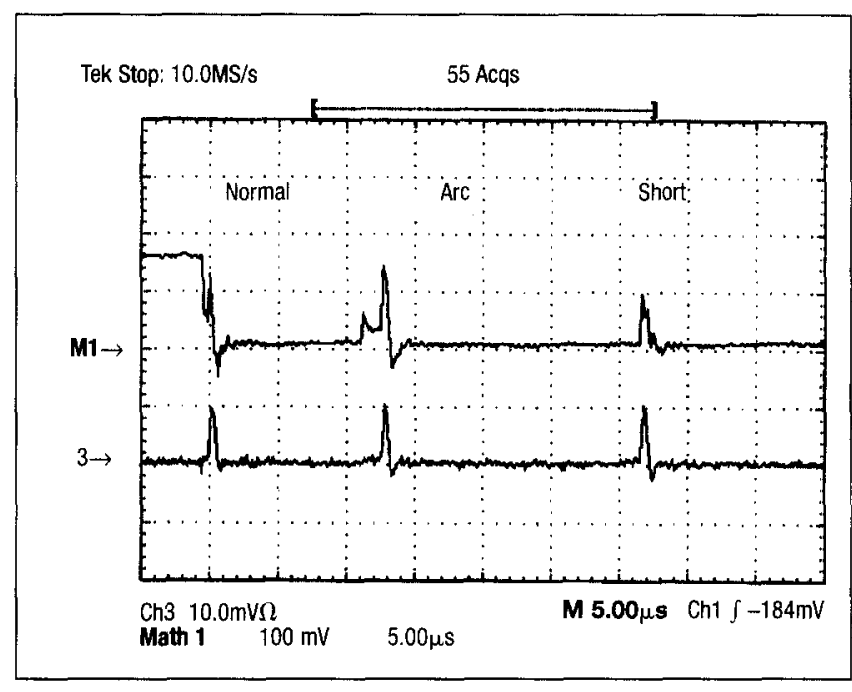

Figure I

Typical Gap Voltage and Current Waveforms of a WEDM Process $(50 \mathrm{~V} / \mathrm{div}$ for gap voltage, $100 \mathrm{~A} / \mathrm{div}$ for gap current, time scale is $5 \mu \mathrm{s} / \mathrm{div}$ )

Table l

Adjustable Parameters of ITRI's WEDM Machine

\begin{tabular}{ll}
\hline Items & Range \\
\hline Pulse on-time & $0.1-3.0 \mu \mathrm{s}(30 \mathrm{steps})$ \\
Pulse off-time & $1.6-48 \mu \mathrm{s}(30 \mathrm{steps})$ \\
Servo reference voltage & $10-70 \mathrm{volts}$ \\
Feedrate override & $0-255 \%$ \\
Wire feed & $0-20 \mathrm{~m} / \mathrm{min}$. \\
Wire tension & $10-2500 \mathrm{gf}$ \\
\hline
\end{tabular}




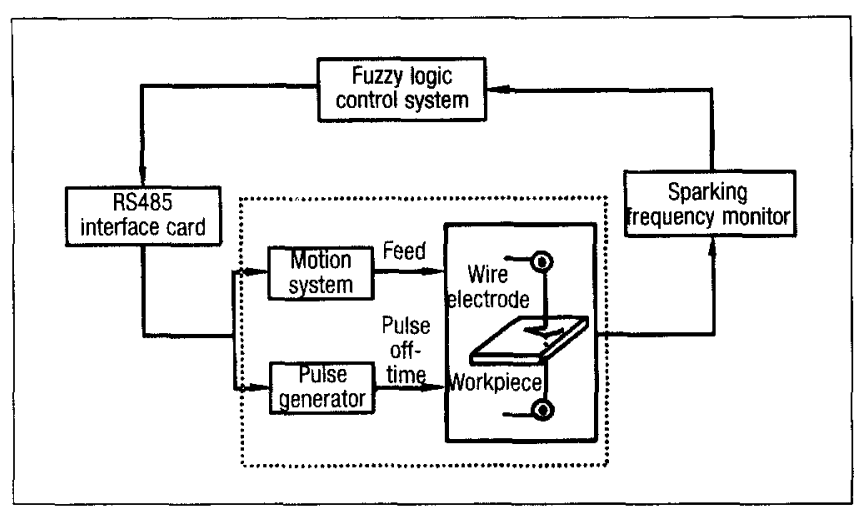

Figure 2

WEDM Sparking Frequency Monitoring and Control System

normal sparks $(\mathrm{Nn})$, and abnormal sparks $(\mathrm{Na})$ (composed of arc discharge and short circuit) in a specific sampling time $(\Delta t)$ are detected. Correspondingly, the instantaneous total sparking frequency can be calculated as $N t / \Delta t$. The normal ratio and abnormal ratio are computed as $\mathrm{Nn} / \mathrm{Nt}$ and $\mathrm{Na} / \mathrm{Nt}$, respectively. The sampling interval is adjustable within the range of 2 to 65535 milliseconds.

An IBM PC/AT-286 is used externally for computation and control purposes. The RS485 interface card is used to handle the $\mathrm{I} / \mathrm{O}$ (input/output) data and to communicate with the IPC (industrial personal computer) of the $\mathrm{CNC}$ unit through an RS232 port. All controllable parameters can be overwritten by the $\mathrm{PC} / \mathrm{AT}-286$ in real time. In the machining process, $x-y$ position data is transferred from the IPC to the PC. Thus, the metal removal rate represented by machining volume per unit time can be computed as: (machining length $x$ thickness of the workpiece $\times$ kerf width) / machining time. By means of this monitoring and control system, the relationship between the sensing parameters (that is, sparking frequency, average gap voltage, normal ratio, and abnormal ratio) and the machining conditions (that is, wire breaking phenomenon, metal removal rate, and surface roughness of the machined part) can be investigated.

\section{Sensing Parameters vs. Metal \\ Removal Rate and Surface Quality}

The symptoms reflected in the variations of pulse trains during the wire rupture process have been identified by previous investigation. ${ }^{18}$ Two types of wire breaking phenomenon are found. The first type is a sudden rise of total sparking frequency. The duration of deterioration ranges from 50 milliseconds to $2 \mathrm{sec}$ onds. This type of wire rupture often occurs when the machining parameter, particularly the pulse on-time or pulse off-time, is changed during the machining process. For the second type of wire breaking, the sparking frequency increases slightly and the abnormal ratio rises to $50 \%$ or more. The duration of premonitory symptoms lasts for 60 seconds or longer before wire rupture. This kind of wire breaking often takes place when a workpiece with a complex shape is machined or a workpiece is machined under a low flushing condition. According to these results, the sparking frequency and abnormal ratio can be used for on-line monitoring and evaluating the gap condition of the WEDM process. The relationships between these two sensing parameters and metal removal rate with respect to feedrate when machining a SKD61 workpiece of $30 \mathrm{~mm}$ height are shown in Figures 3 and 4. As illustrated in Figure 3, there exists an inverse relationship between the normal ratio (or gap voltage) and feedrate. The MRR is increased first with the feedrate, and it reaches the maximum value when the abnormal ratio is $54 \%$. Once the feedrate is increased to more than $1.2 \mathrm{~mm} / \mathrm{min}$, the MRR starts to decrease. The reason for decreasing MRR is due to a short circuit detection function designed by the machine tool builder. The table is withdrawn and the feed is commenced again instantaneously by the motion system of the WEDM machine when the total number of successive abnormal sparks reaches a spe-

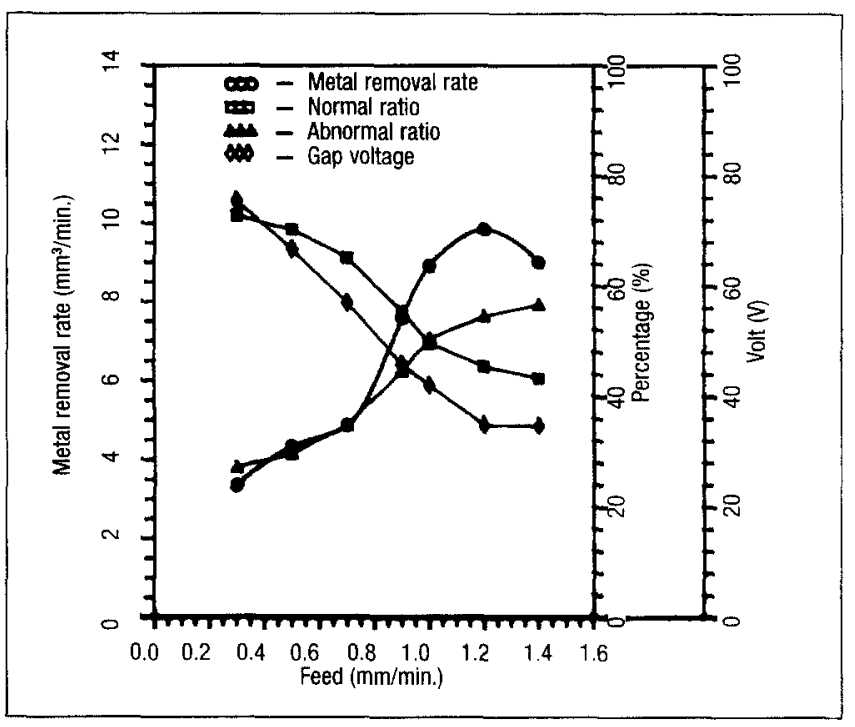

Figure 3

Relation Between Sensing Parameters and MRR with Respect to Feedrate (on-time: $500 \mathrm{~ns}$; off-time: $11.2 \mu \mathrm{s}$; wire speed: $7 \mathrm{~m} / \mathrm{min}$.; wire tension: $600 \mathrm{gf}$; flushing pressure: upper $=\mathbf{2}$ bars, lower $=2$ bars; wire: copper $[\phi 0.25 \mathrm{~mm}])$ 
cific value. Under the same machining condition, it was found that the surface quality of the machined part slightly deteriorates as the feedrate increases accompanied with the decrease of the normal ratio and gap voltage. Figure 4 shows the relationship between the sparking frequency and MRR with respect to feedrate. This figure indicates that the sparking frequency is proportional to MRR. Based on Figures 3 and 4 , it is clear that the abnormal ratio should be kept within the range of $40 \%$ to $50 \%$ so that a stable and high metal removal rate state can be maintained. Similar relationships as those shown in Figures 3 and 4 are obtained when a SKD11 workpiece with different height is machined. According to some experimental results, the optimal value of the abnormal ratio ranges from $40 \%$ to $60 \%$ depending heavily on the pulse on-time of power settings. The higher the discharge energy, the higher the optimal value. For this machine, the abnormal ratios of $40 \%$ to $50 \%$ and $55 \%$ to $60 \%$ are found to be suitable for finish and rough machining conditions, respectively.

\section{Multivariable and Multiregion Fuzzy Controller}

The objective of adaptive control of the WEDM process is to control the feed of the servo mechanism and the power settings in such a way as to maintain a high metal removal rate during roughing and optimal and stable machining during finishing, and to achieve good control performance when there is disturbance. In this section, a multivariable and three-region fuzzy controller that uses the abnormal ratio and the sparking frequency as controller input, and changes in both control parameters (that is, servo feed and pulse off-time) as controller output is proposed to solve the ACO problem of WEDM. The sparking frequency is proportional to MRR, and it is closely related to wire breaking. Thus, the operating condition is divided into safe, critical, and dangerous regions depending on the level of the sparking frequency. In the critical and dangerous regions, control rules are designed to avoid wire rupture. In the safe region, control strategy should be taken to maintain stable machining and high metal removal rate. By regulating both the servo feed and the pulse off-time, the abnormal ratio is controlled at an optimal level while keeping the sparking frequency under a safe level for wire rupture prevention. The fuzzy control framework is depicted in Figure 5. In

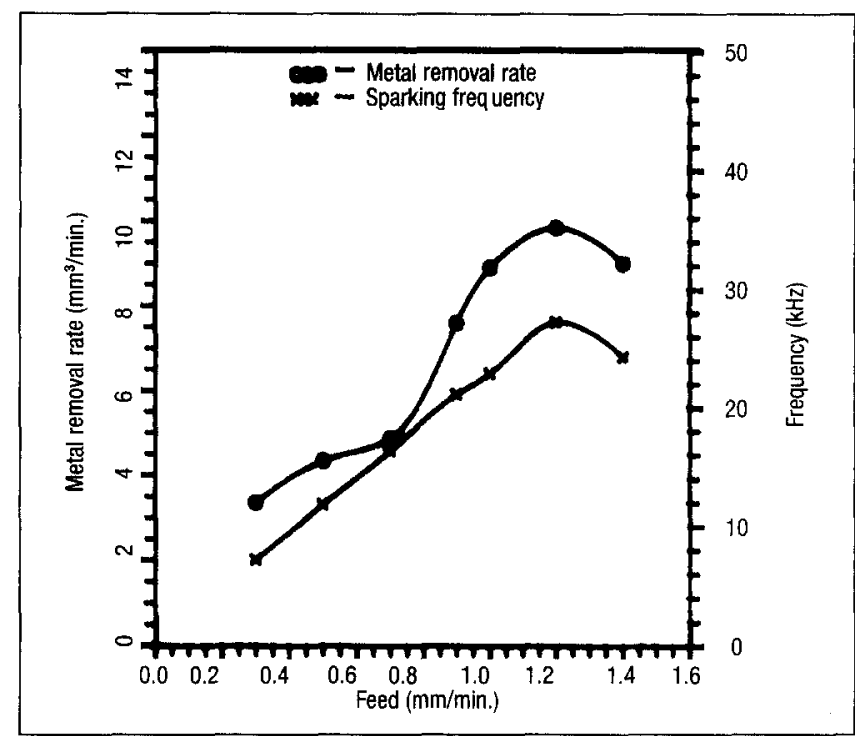

Figure 4

Relation Between Sparking Frequency and MRR with Respect to Feedrate (on-time: $500 \mathrm{~ns}$; off-time: $11.2 \mu \mathrm{s}$; wire speed: $7 \mathrm{~m} / \mathrm{min}$. wire tension: 600 gf; flushing pressure: upper $=\mathbf{2}$ bars, lower $=\mathbf{2}$ bars; wire: copper [ $\phi 0.25 \mathrm{~mm}])$

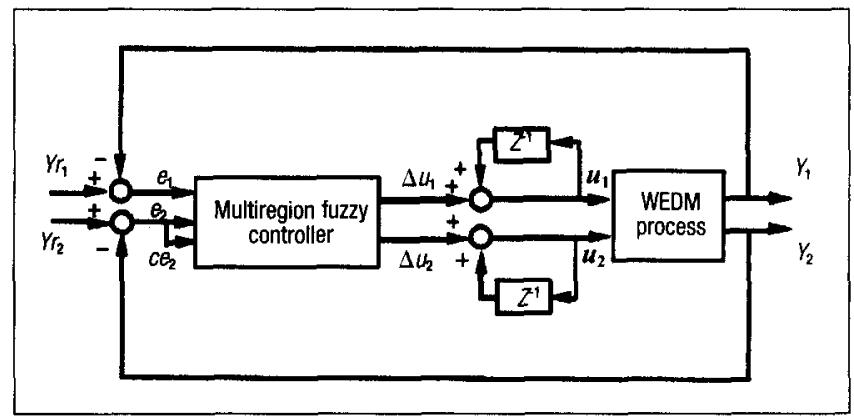

Figure 5

Schematic Diagram for a Multivariable and Multiregion Fuzzy Controller

addition to the use of error $\left(e_{2}\right)$ and change of error $\left(c_{2}\right)$ of the abnormal ratio, error of the sparking frequency $\left(e_{1}\right)$ is also used as an input to determine in which region the process is operating. The functional relationship represented by such a fuzzy controller can be described as follows:

$$
\begin{aligned}
& \Delta u_{1}=F_{1}\left(e_{1}, e_{2}, c e_{2}\right) \\
& \Delta u_{2}=F_{2}\left(e_{1}, e_{2}, c e_{2}\right)
\end{aligned}
$$

where $F_{1}(\bullet)$ and $F_{2}(\cdot)$ stand for the nonlinear relationship of the fuzzy controller, and $\Delta u_{1}$ and $\Delta u_{2}$ represent change in the feed control action and change in the pulse off-time control action, respectively. Detailed design considerations are given in the following. 
According to the targets of the control system, the input variables of the fuzzy controller can be formally defined as follows:

$$
\begin{aligned}
e_{1} \equiv & \text { sparking frequency error } \\
= & \text { (reference sparking frequency }- \text { sparking } \\
& \text { frequency) } * G E_{1} \\
e_{2} \equiv & \text { abnormal ratio error } \\
= & \text { (reference abnormal ratio - abnormal ratio) } \\
& * G E_{2} \\
c e_{2} \equiv & \text { change of abnormal ratio error } \\
= & \text { (current abnormal ratio error - previous } \\
& \text { abnormal ratio error) } * G C E_{2}
\end{aligned}
$$

where $G E_{1}, G E_{2}$, and $G C E_{2}$ are scaling factors and their values are found to be $G E_{1}=0.25, G E_{2}=10$, and $G C E_{2}=8$, respectively, in this case. The reference frequency $\left(Y_{r 1}\right)$ and reference abnormal ratio $\left(Y_{r 2}\right)$ vary with the discharge energy. Their choices are to maximize metal removal rate under the constraint of keeping the wire electrode in the safe operating region. Taking the experimental results as shown in Figures 3 and 4 as an example, the optimal value of the abnormal ratio can be chosen as $40 \%$. The corresponding mean sparking frequency plus three times the standard deviation of the sparking frequency can be taken as the reference sparking frequency, and its value is $30 \mathrm{kHz}$ in this case. Three linguistic sets on the domains of definition of $e_{1}$, namely Positive $(P)$, Zero $(\mathrm{ZO})$, and Negative $(\mathrm{N})$, are specified. They correspond, respectively, to safe region, critical region, and wire rupture region. To reduce the computation task, five linguistic fuzzy variables for fuzzification of the input terms $\left(e_{2}\right.$ and $\left.c e_{2}\right)$ are specified. They are Negative Big (NB), Negative Small (NS), Zero (ZO), Positive Small (PS), and Positive Big (PB). Moreover, five linguistic variables of the change in control action (either $\Delta u_{1}$ or $\Delta u_{2}$ ) are chosen as NB, NS, ZO, PS, and PB. The choice of these five fuzzy variables is a compromise between easier implementation and sensitivity of the controller. The membership function of linguistic values of input (that is, $e_{1}, e_{2}$, and $c e_{2}$ ) and output (that is, $\Delta u_{1}$ and $\Delta u_{2}$ ) of the controller are illustrated in Figures $6 a, 6 b$, and $6 c$, respectively. It is an isosceles triangle-shaped function because of convenient manipulation. Fuzzy inference rules for the multivariable and multiregion fuzzy controller are described as follows:

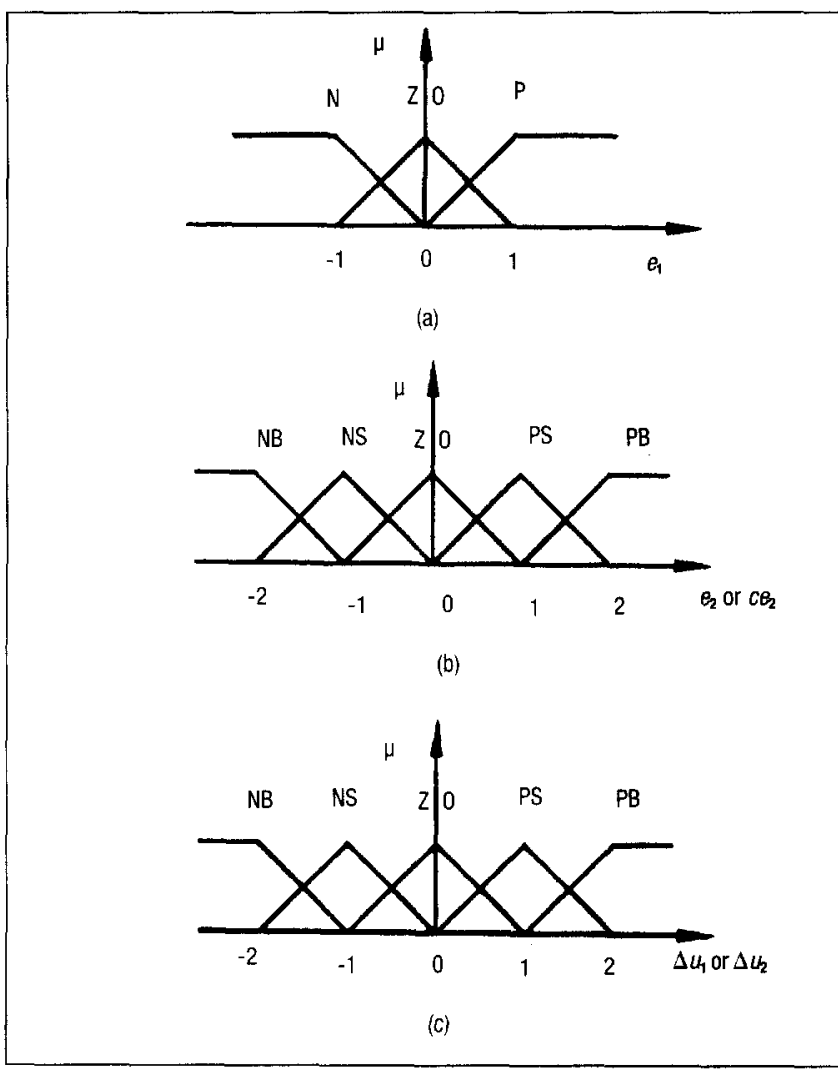

Figure 6

Membership Function Definition for the Fuzzy Controller (a) $e_{1}$, (b) $e_{2}$ or $c e_{2}$, (c) $\Delta u_{1}$ or $\Delta u_{2}$

$R_{1}$ : If $e_{1}$ is $A_{1}$ and $e_{2}$ is $B_{1}$ and $c e_{2}$ is $C_{1}$, then $\Delta u_{1}$ is $D_{1}$ and $\Delta u_{2}$ is $E_{1}$

$R_{n^{2}(i-1)+n(j-1)+k}$ : If $e_{1}$ is $A_{i}$ and $e_{2}$ is $B_{j}$ and $c e_{2}$ is $C_{k}$, then $\Delta u_{1}$ is $D_{l}$ and $\Delta u_{2}$ is $E_{m}$

where $A_{i}, B_{j}, C_{k}, D_{l}$, and $E_{m}$ are linguistic values of linguistic variables $e_{1}, e_{2}, c e_{2}, \Delta u_{1}$, and $\Delta u_{2}$, respectively, with $i=1,2,3$, and $j, k, l, m=1,2 \ldots .5$, and $n=5$ in this case. Based on the operator's experience and expert's knowledge, fuzzy rules for three-region fuzzy controllers are designed according to the following:

1. When the sparking frequency is in the safe region (that is, $e_{1}$ : Positive), control action should be taken by rapidly increasing the feedrate and decreasing the pulse off-time providing that the abnormal ratio is less than the predetermined value. If the abnormal ratio is larger than 
the predetermined value, the pulse off-time should be increased and the feedrate should be slowly reduced to improve the bad gap condition, thereby keeping the sparking frequency in the safe operating region.

2. When the sparking frequency is in the critical region ( $e_{1}$ : Zero), the feedrate should be slowly increased, and the pulse off-time should remain constant providing that the abnormal ratio is less than the preset value. When the abnormal ratio reaches the predetermined level, the pulse offtime should be slightly increased and the feedrate should remain constant so that the sparking frequency will not reach the dangerous region.

3. When the sparking frequency is in the dangerous region, control action should be taken by greatly increasing the pulse off-time and decreasing the feedrate for fear of wire breaking.

The fuzzy control rules are given in Table 2. The max-min inference method is used to perform the fuzzy reasoning on the linguistic control rules. ${ }^{19}$ The center-of-area method is employed for the purpose of defuzzification, and the method can be represented by the following:

$$
\begin{aligned}
\Delta u_{1}= & \frac{\sum_{j=1}^{n} \mu_{D}\left(u_{j}\right) \cdot u_{j}}{\sum_{j=1}^{n} \mu_{D}\left(u_{j}\right)} \times G U_{1} \\
\Delta u_{2}= & \frac{\sum_{j=1}^{n} \mu_{E}\left(v_{j}\right) \cdot v_{j}}{\sum_{j=1}^{n} \mu_{E}\left(v_{j}\right) \cdot v_{j}} \times G U_{2}
\end{aligned}
$$

where in the above equations $\Delta u_{1}$ and $\Delta u_{2}$ are the output of the controller, $u_{j}$ and $v_{j}$ are the support values at which the membership function reaches the maximum value of $\mu_{D}\left(u_{j}\right)$ and $\mu_{E}\left(v_{j}\right)$, respectively, and $n$ is the number of quantification levels of the output.

The real control signals applied to the process can be calculated by the following:

$$
\begin{aligned}
& u_{1}(k T)=u_{1}((k-1) T)+\Delta u_{1}(k T) \\
& u_{2}(k T)=u_{2}((k-1) T)+\Delta u_{2}(k T)
\end{aligned}
$$

\begin{tabular}{|c|c|c|c|c|c|}
\hline \multicolumn{6}{|c|}{$\begin{array}{c}e_{1}: \text { POSITIVE } \\
\Delta u_{1}\end{array}$} \\
\hline$\left.e_{2}\right|^{c_{2}}$ & PB & PS & $\mathrm{ZO}$ & NS & NB \\
\hline PB & PB & PB & $\mathrm{PB}$ & PS & PS \\
\hline PS & PB & PB & PS & $\mathrm{ZO}$ & PS \\
\hline $\mathrm{ZO}$ & PB & PS & $\mathrm{ZO}$ & NS & NS \\
\hline NS & NS & NS & NS & NS & NB \\
\hline NB & NB & NB & NB & NB & NB \\
\hline \multicolumn{5}{|c|}{$\Delta u_{2}$} & NB \\
\hline PB & PB & PB & PB & NS & NS \\
\hline PS & PB & PS & PS & $\mathrm{ZO}$ & NS \\
\hline $\mathrm{ZO}$ & PB & PS & $\mathrm{ZO}$ & NS & NB \\
\hline NS & NB & NS & NS & NS & NB \\
\hline NB & NB & $\mathrm{NB}$ & NB & NB & NB \\
\hline \multicolumn{6}{|c|}{$\begin{array}{c}e_{1}: \text { ZERO } \\
\Delta u_{1}\end{array}$} \\
\hline$\left.e_{2}\right|^{k e_{2}}$ & PB & PS & $\mathrm{ZO}$ & NS & NB \\
\hline PB & PS & PS & PS & NS & NS \\
\hline PS & PS & PS & PS & $\mathrm{ZO}$ & NS \\
\hline $\mathrm{ZO}$ & PS & NS & $\mathrm{ZO}$ & NS & NB \\
\hline NS & NB & NS & NS & NS & NB \\
\hline NB & NB & NB & NB & NB & NB \\
\hline$\left.e_{2}\right|^{k e_{2}}$ & PB & PS & ${ }^{2} \mathrm{ZO}$ & NS & NB \\
\hline PB & $\mathrm{ZO}$ & $\mathrm{ZO}$ & $\mathrm{zO}$ & NS & NS \\
\hline PS & $\mathrm{ZO}$ & $\mathrm{ZO}$ & $\mathrm{ZO}$ & $\mathrm{ZO}$ & NS \\
\hline $\mathrm{ZO}$ & NS & NS & NS & NS & $\mathrm{NB}$ \\
\hline NS & NB & NB & NB & NB & NB \\
\hline NB & NB & $\mathrm{NB}$ & NB & NB & NB \\
\hline \multicolumn{6}{|c|}{$\begin{array}{c}e_{1}: \text { NEGATIVE } \\
\Delta u_{1}\end{array}$} \\
\hline$\left.e_{2}\right|^{C e_{2}}$ & PB & PS & $\mathrm{ZO}$ & NS & $\mathrm{NB}$ \\
\hline PB & $\mathrm{ZO}$ & $\mathrm{ZO}$ & ZO & $\mathrm{ZO}$ & NS \\
\hline PS & NS & NS & NS & NS & NS \\
\hline $\mathrm{ZO}$ & NS & NS & NS & NS & NB \\
\hline NS & NB & NB & NB & NB & $\mathrm{NB}$ \\
\hline NB & NB & NB & NB & NB & $\mathrm{NB}$ \\
\hline$\left.e_{2}\right|^{c e_{2}}$ & PB & PS & $\mathrm{i}_{2} \mathrm{ZO}$ & NS & NB \\
\hline PB & NS & NS & NS & NS & NS \\
\hline PS & NB & NB & NB & NB & NB \\
\hline $\mathrm{ZO}$ & NB & NB & NB & NB & NB \\
\hline NS & NB & NB & NB & NB & NB \\
\hline NB & NB & NB & NB & NB & NB \\
\hline
\end{tabular}

Table 2

Fuzzy Rules for a Multivariable and Three-Region Fuzzy Controller

where $u_{1}$ represents feedrate, $u_{2}$ is defined as the reciprocal of pulse off-time $\left(t_{0}\right)$, that is, $u_{2}=1 / t_{0}$, and $k T$ is the $k$ th sampling time instant. 


\section{Experimental Results}

An IBM PC/AT-286 microcomputer is used as the hardware for the proposed controller, and the control law is written in $\mathrm{C}$ language. The sampling time is chosen as $\mathbf{4 0}$ milliseconds. To verify the applicability of the developed monitoring and control system and the effectiveness of the proposed control law, three machining conditions (finish machining, rough machining, and changing set value during machining) encountered in actual industrial practice are examined. The experimental results are presented and discussed in the following subsections.

\section{Finish Machining}

It is well known that the purpose of finish machining is to modify the residual stresses and thermal stresses arising from rough machining, reduce a recast layer, and improve surface quality and geometrical accuracy of the machined part. Therefore, besides the targets of the control system, variation of
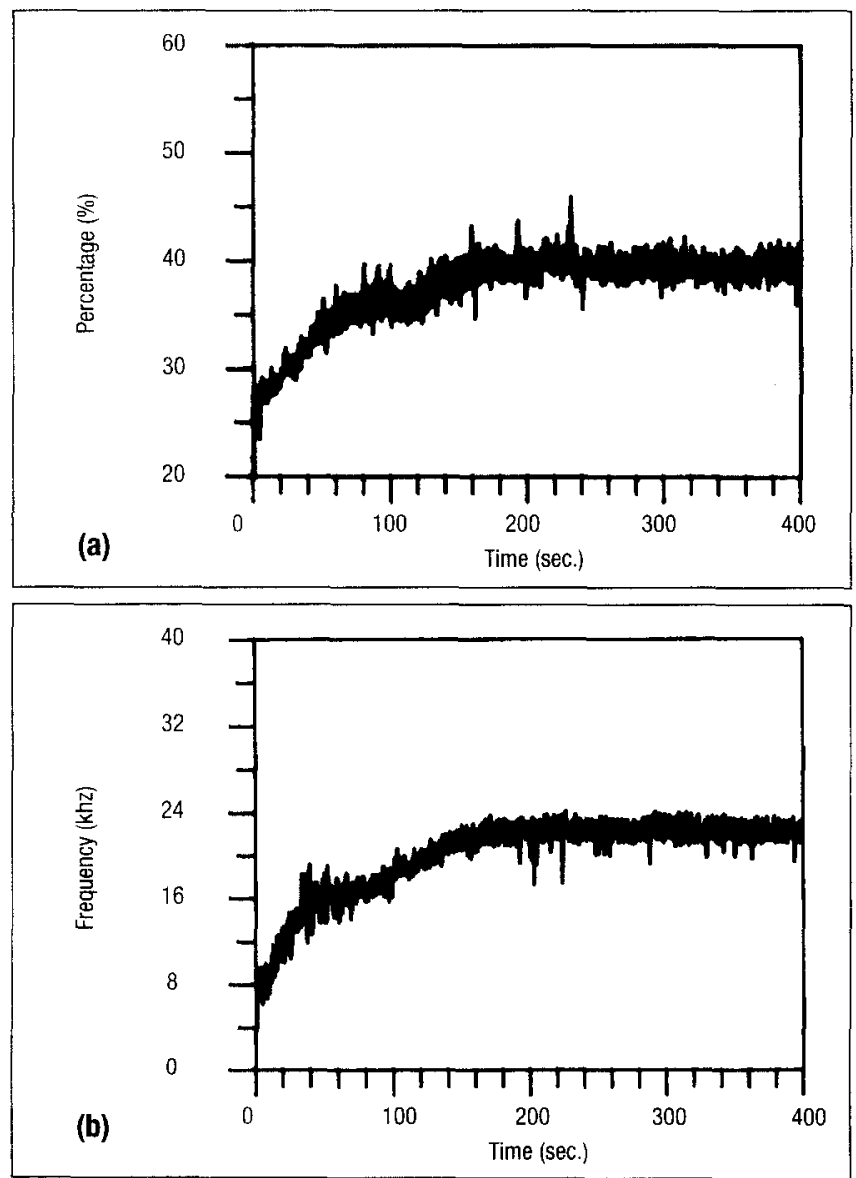

the feedrate control parameter $(\Delta f)$ during the steady machining state is also constrained to a narrow bound to keep a constant gap width. In this paper, the constraint is specified as: $|\Delta f| \leq 0.1 \mathrm{~mm} / \mathrm{min}$. Figures $7 a-e$ show the time evolution of the process output, abnormal ratio, sparking frequency, and average gap voltage, together with the time history of
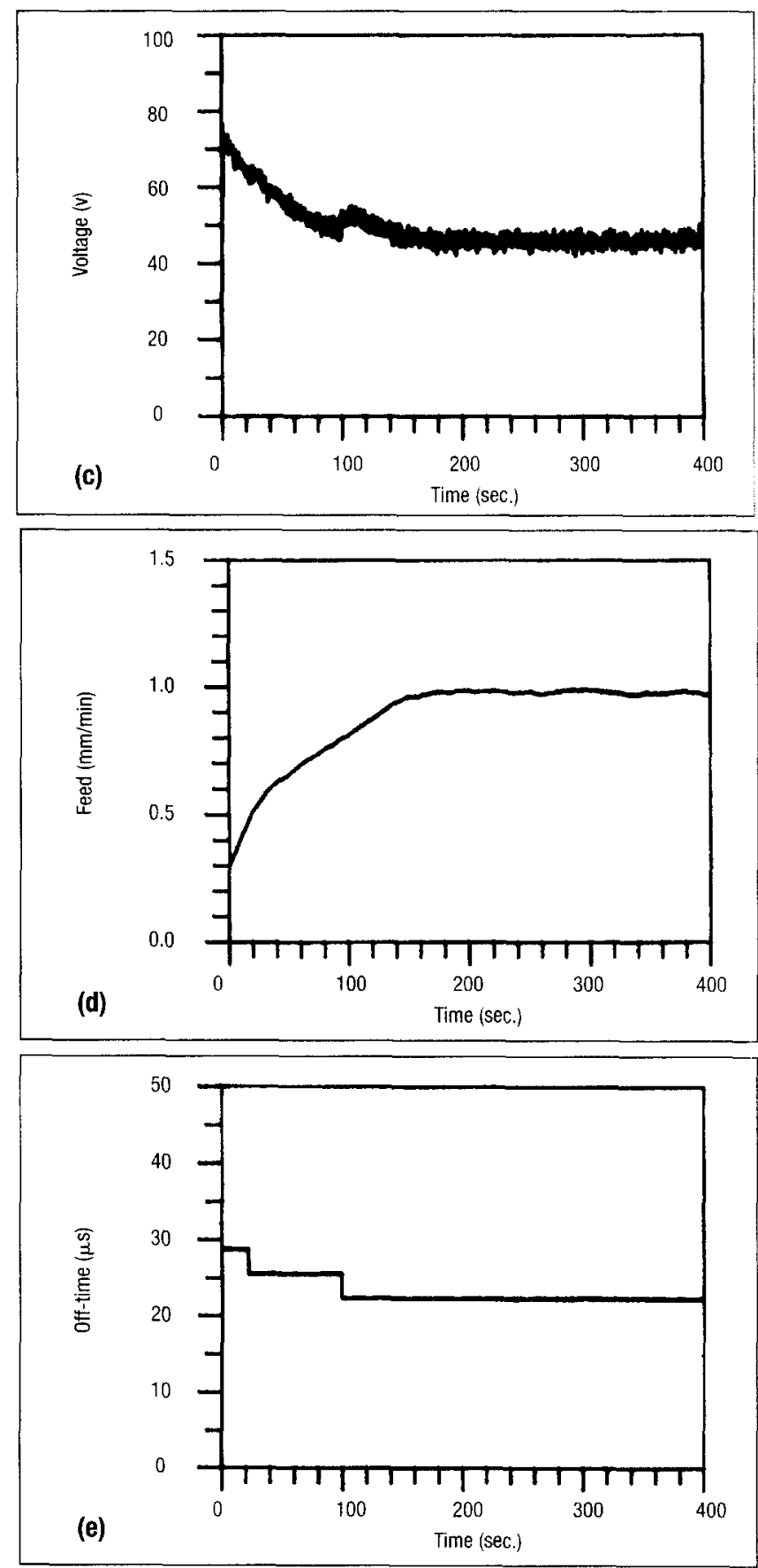

Figure 7

Time Evolution of (a) Abnormal Ratio, (b) Sparking Frequency, (c) Average Gap Voltage, (d) Feed, and (e) Off-Time with the Sparking Frequencs Monitoring and Control System During Finish Machining 
both controllers (that is, feedrate and pulse off-time) when a workpiece of SKD61 with a thickness of 30 $\mathrm{mm}$ is machined under finish machining condition. Machining and controller parameters are Test No. 1 given in Table 3. As illustrated in Figure $7 a$, the abnormal ratio is rapidly controlled from $25 \%$ to the optimal value (40\%) within 150 seconds without any oscillation. Metal removal process of WEDM is much slower as compared with the servo mechanism of motion systems. If the feedrate and pulse off-time are adjusted too fast during transient machining state, the machining process will be unstable. As a result, the bad gap condition may cause surface damage and wire rupture. Thus, the rising time (150 seconds) shown in this figure is appropriate for controlling this process. The sparking frequency is kept under the safe level during machining, as shown in Figure $7 b$. The corresponding average gap voltage is maintained at a level of 45 volts during operating machin- ing condition, as shown in Figure 7c. Figures $7 d$ and $7 e$ show, respectively, the time evolution of the feedrate $(f)$ and the pulse off-time with initial values of $f=0.3 \mathrm{~mm} / \mathrm{min}$. and $t_{0}=32 \mu \mathrm{s}$. As the state of the process reaches the predetermined operating condition, both controller parameters are slightly regulated to achieve the desired machining state.

\section{Rough Machining}

Figures $8 a-d$ show the time evolution of the process output, abnormal ratio, and sparking frequency, together with the time history of both controllers when a workpiece of SKD11 with a thickness of $50 \mathrm{~mm}$ is machined under rough machining condition. Machining and controller parameters are Test No. 3 in Table 3. Figure $8 a$ shows that the abnormal ratio is controlled from the initial level of $40 \%$ to the desired level of $60 \%$ without any oscillation. As shown in Figure $8 b$, the sparking frequency
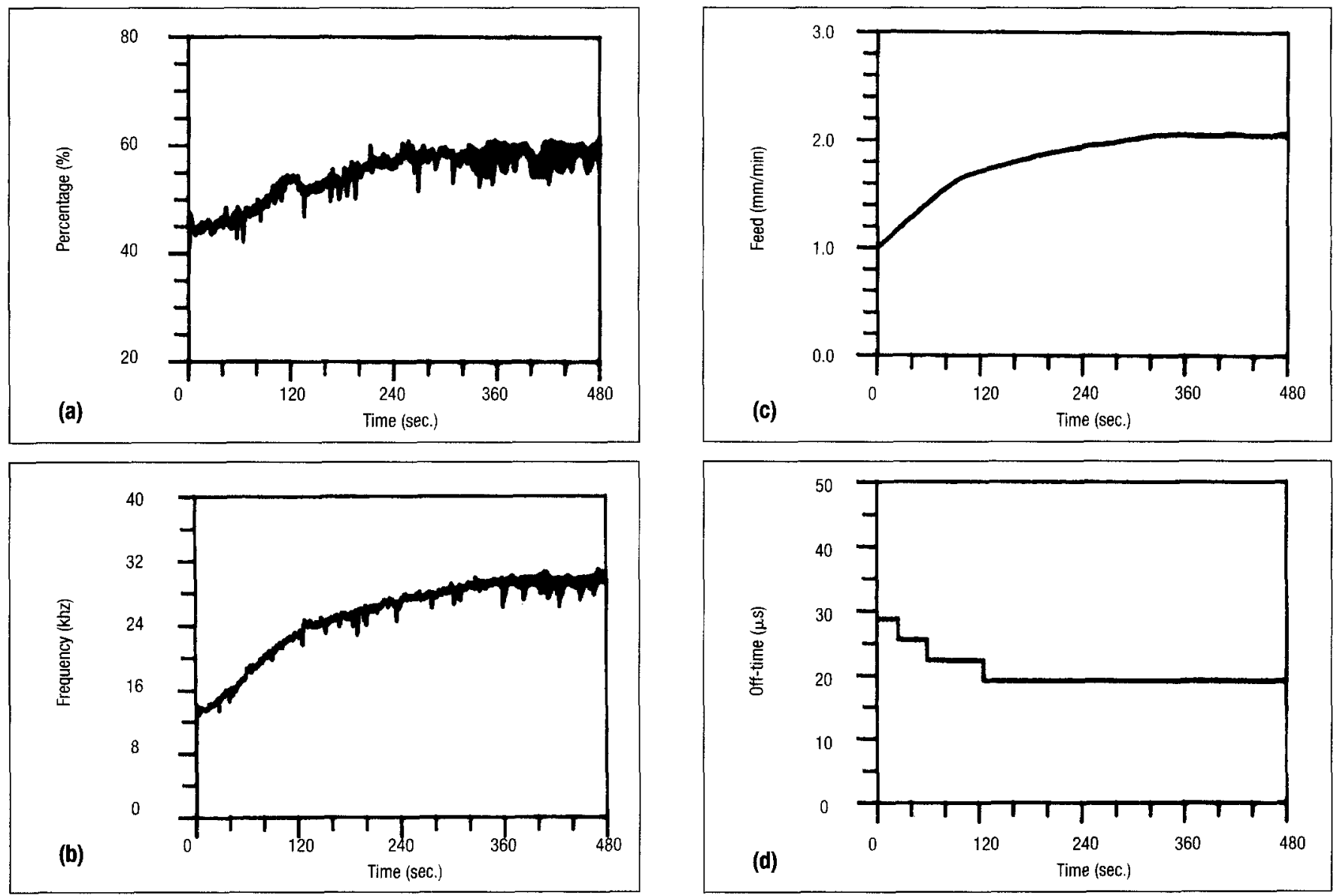

Figure 8

Time Evolution of (a) Abnormal Ratio, (b) Sparking Frequency, (c) Feed, and (d) Off-Time with the Sparking Frequency Monitoring and Control System During Rough Machining 
Table 3

Machining Parameters and Controller Parameters Used in Experiments

\begin{tabular}{|c|c|c|c|c|c|c|c|c|c|}
\hline \multirow[b]{2}{*}{ Test No. } & \multicolumn{5}{|c|}{ Machining Parameters } & \multicolumn{4}{|c|}{ Controller Parameters } \\
\hline & $\begin{array}{c}\text { On-time } \\
\text { [ns] }\end{array}$ & $\begin{array}{c}\text { Wire } \\
\text { speed } \\
{[\mathrm{m} / \mathrm{min} .]}\end{array}$ & $\begin{array}{c}\text { Wire } \\
\text { tension } \\
{[\mathrm{gf}]}\end{array}$ & $\begin{array}{c}\text { Flushing } \\
\text { upper } \\
\text { [bar }\end{array}$ & $\begin{array}{l}\text { Pressure } \\
\text { lower } \\
\text { r] }\end{array}$ & $\begin{array}{c}\mathrm{GU}_{1} \\
\left(\mathrm{x} 10^{-4}\right)\end{array}$ & $\begin{array}{c}\mathrm{GU}_{2} \\
\left(\times 10^{-4}\right)\end{array}$ & $\begin{array}{c}\mathrm{Yr}_{1} \\
{[\mathrm{kHz}]}\end{array}$ & $\begin{array}{l}\mathrm{Yr}_{2} \\
{[\%]}\end{array}$ \\
\hline 1 & 500 & 7 & 800 & 2 & 2 & 1.8 & 0.8 & 30 & 40 \\
\hline 2 & 700 & 8 & 600 & 5 & 5 & 2 & 0.4 & 30 & 55 \\
\hline 3 & 1000 & 13 & 500 & 7 & 6 & 2 & 1 & 35 & 60 \\
\hline
\end{tabular}

is monitored and controlled in a safe region during machining. These two figures show that the desired high metal removal state can be maintained without causing unstable machining and wire rupture. The feedrate is regulated, and the pulse off-time is kept at the level of $19.2 \mu \mathrm{s}$, as illustrated in Figures $8 c$ and $8 d$, respectively. During the operating machining condition, the machining speed is kept at the level of
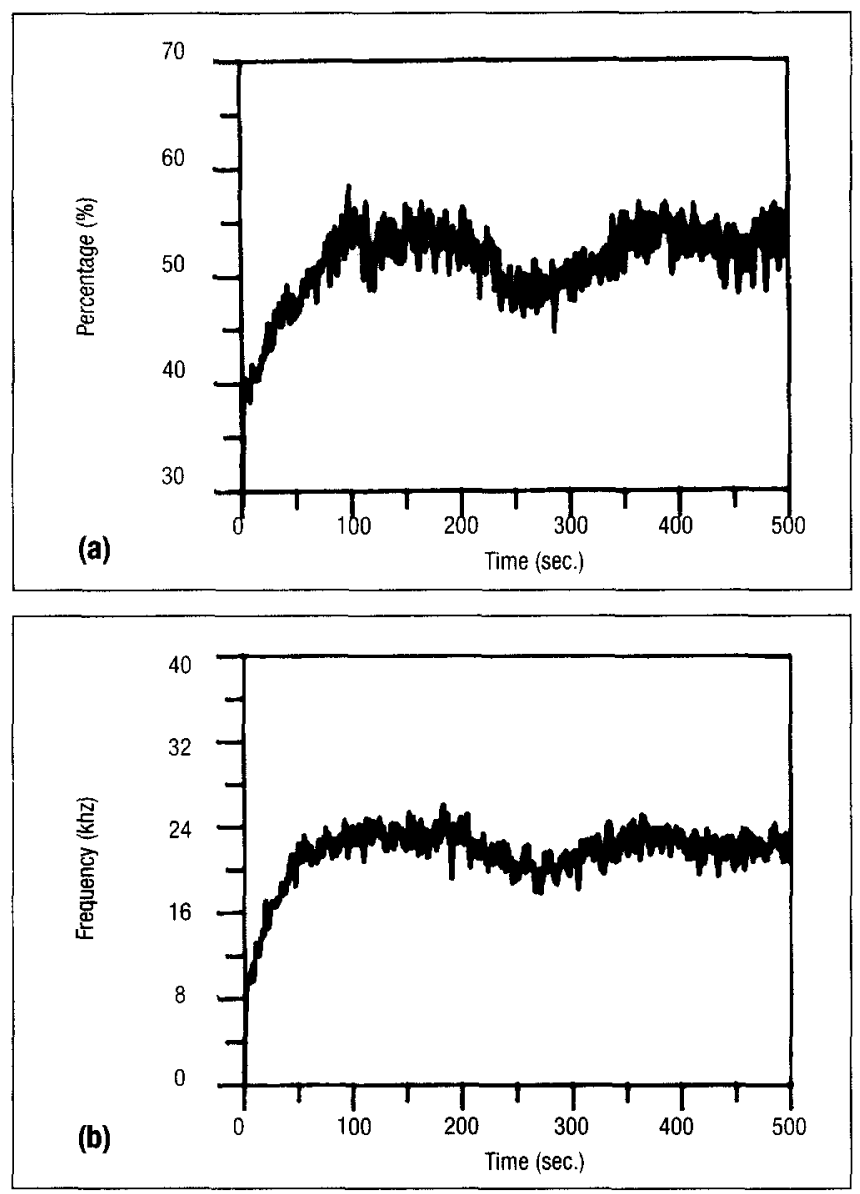

$100 \mathrm{~mm}^{2} / \mathrm{min}$. This experiment demonstrates that the developed control system can be applied to the rough machining condition of the WEDM process without the risk of wire rupture

\section{Changing Set Value During Machining}

Figures $9 a-d$ show the experimental results when a workpiece of SKD1l with a thickness of $50 \mathrm{~mm}$ is
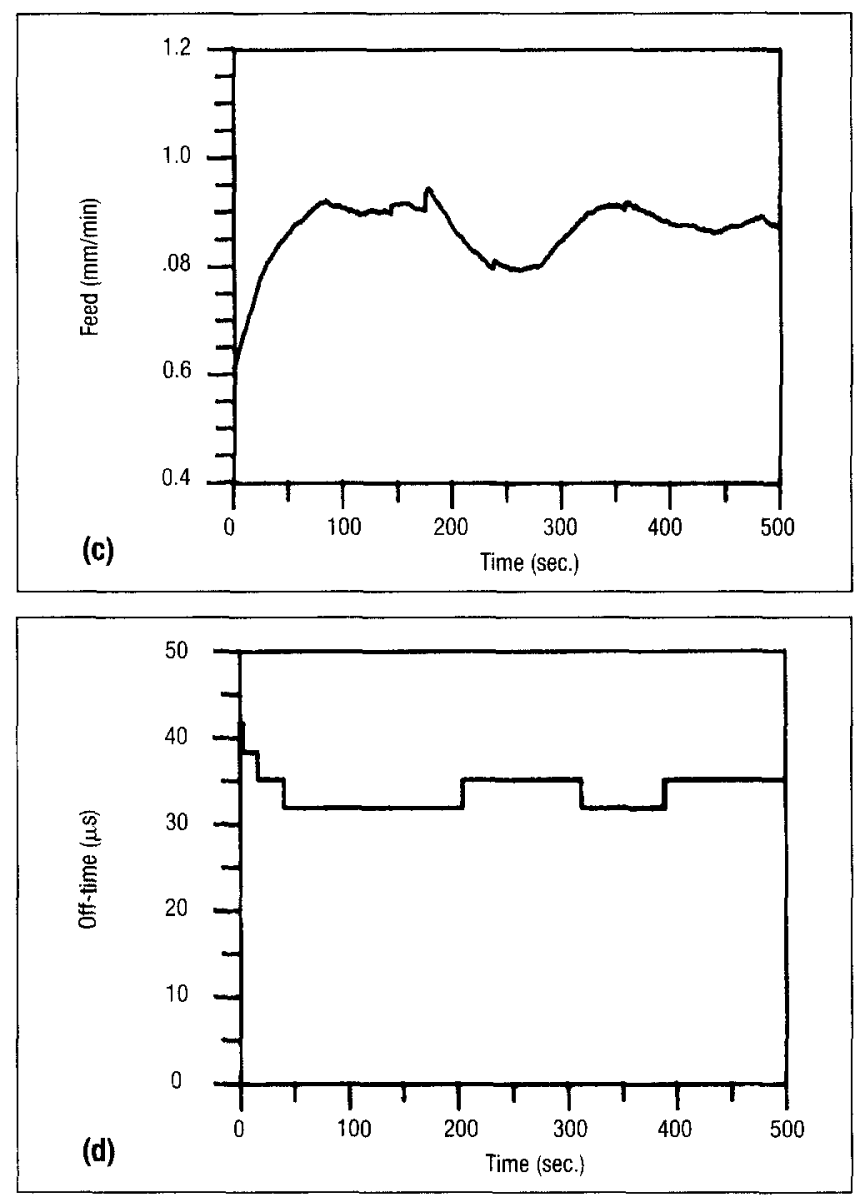

Figure 9

Time Evolution of (a) Abnormal Ratio, (b) Sparking Frequency, (c) Feed, and (d) Off-Time with the Sparking Frequency Monitoring and Control System When the Set Value is Changed During Machining Condition 
machined and the abnormal ratio is varied during the machining process. Machining and controller parameters are given in Table 3 as well (Test No. 2). The abnormal ratio was changed from $55 \%$ to $50 \%$ at the time instant of 180 seconds, and after a predetermined duration (100 seconds) its value was set to $55 \%$ again. Figure $9 a$ demonstrates that the monitoring and control system can follow the change of set value, and the process can be recovered to the desired machining state through the adjustment of both control parameters. Figure $9 b$ shows that the sparking frequency is correspondingly changed when there is a change of the abnormal ratio during machining. Its value, however, is kept under a reference level without the risk of wire breaking. The time evolution of the feedrate and pulse off-time is shown in Figures $9 c$ and $9 d$, respectively. As shown in these two figures, both control parameters can be automatically adjusted by the proposed control strategy to adapt the change of set value. This experiment proves that the proposed fuzzy control strategy has good tracking ability to follow the change of set value without causing unstable machining and steady error. When a working path contains sharp corners, the servo feed and the pulse off-time are simultaneously adjusted by modifying the set value, similar to those in this experiment, so that wire breaking can be avoided during the machining of sharp angles. Therefore, appropriate action during the machining of a sharp corner can be taken by means of the developed monitoring and control system.

For comparison purposes, control by using a conventional gap voltage control system with $\mathrm{p}$-control method under the same condition of finish machining (Figure 7) is conducted. Figures $10 a$ and $10 \mathrm{~b}$ show the time evolution of average gap voltage and feed respectively. By comparing Figure 7 with Figure 10, it can be seen that there is a steady state error of 10 volts (the reference value is denoted by a dashed line). There is a large change of feed at the beginning of the experiment due to a fixed gain. In addition, feed shows chattering (high-frequency variation) behavior. Similarly, control under the condition of changing set point value during machining (Figure 9) is carried out. The results are shown in Figures $11 a$ and $11 b$. The same results as stated previously are observed. The overall comparison of the performance of the proposed control strategy with conventional gap voltage control system using the p-control method is given in Table 4. It can be concluded that the developed control system has better control performance than that of the conventional control method.

\section{Conclusions}

This paper reports a new sparking frequency monitoring and adaptive control system for the WEDM process. The fuzzy logic strategy has been selected to implement adaptive control optimization of the WEDM process. Experimental results illustrate that the fuzzy controller is suitable for such an uncertain and complicated process where no mathematical equations can be deduced to describe it. The specific conclusions are listed as follows:

1. The abnormal ratio and the sparking frequency not only can be employed to monitor and evalu-

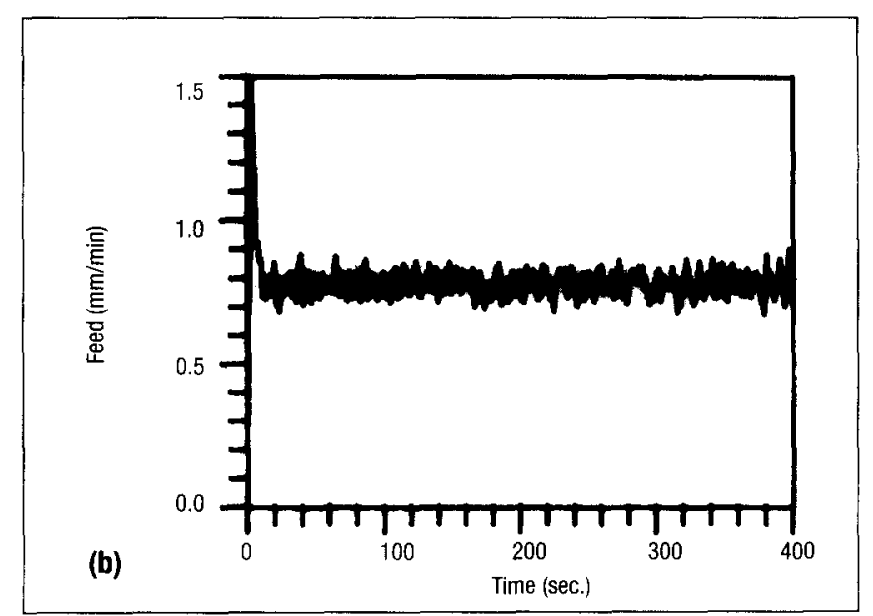



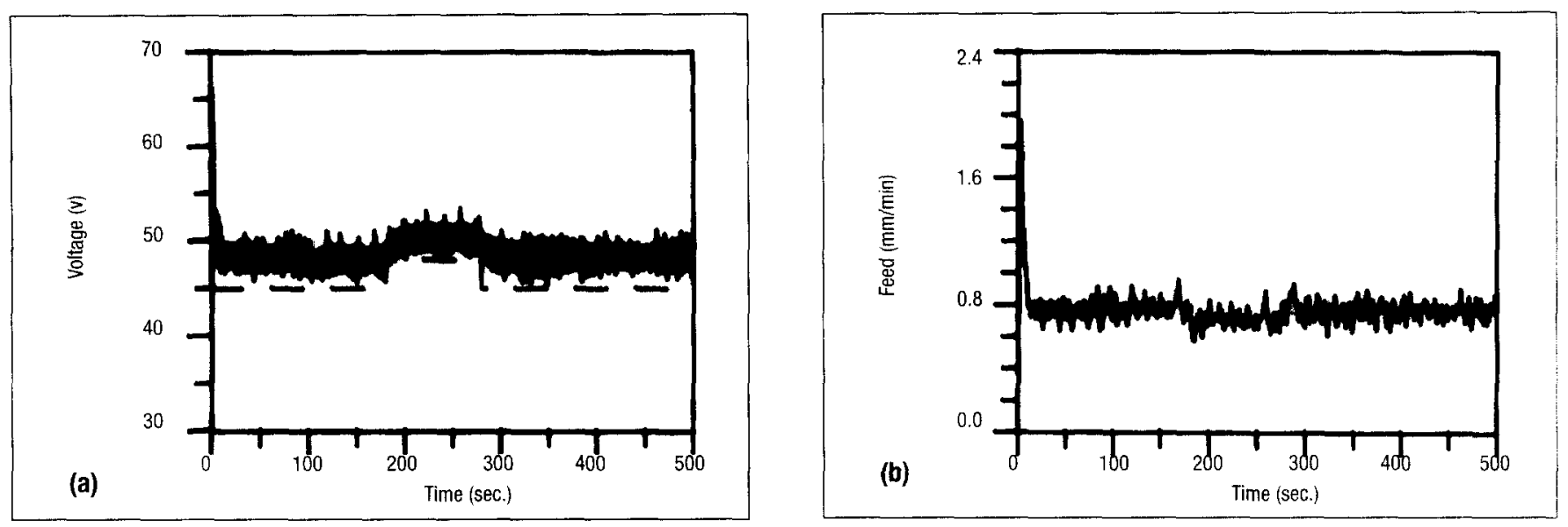

Figure 11

Time Evolution of (a) Gap Voltage and (b) Feed for Gap Voltage Control System with P-Control Method When the Set Value is Changed During Machining Condition

Table 4

Comparison of Gap Voltage Control System with P-Control Method and Sparking Frequency Monitoring and Control System

Properties Gap Voltage Control System Sparking Frequency Monitoring and Control System

\begin{tabular}{lcc} 
Transient response & Poor & Good \\
Tracking error & Poor & Good \\
Machining stability & Poor & Good \\
Control parameter & Simple & Fair \\
Wire rupture prevention & Poor & Good \\
\hline
\end{tabular}

ate the gap condition, they can also be used as control parameters for adaptive control of WEDM.

2. A multivariable and three-region fuzzy controller is proposed to solve the ACO problems for WEDM. Experimental results demonstrate that stable, optimal, and high-speed machining can be achieved, while at the same time wire rupture can be prevented, by employing the developed sparking frequency monitoring and control system. The developed system increases the machining speed and improves the machining stability, and it is better than the gap voltage control system with p-control method.

\section{Acknowledgments}

Support from the National Science Council, Taiwan, is gratefully acknowledged.

\section{References}

1. R. Snoeys, D.F. Dauw, J.P. Kruth, "Survey of EDM Adaptive Control in Electro Discharge Machining," Journal of Mfg. Systems (v2, n2, 1983), pp $147-164$.

2. M. Weck and J.M. Dehmer, "Analysis and Adaptive Control of EDM
Sinking Process Using the Ignition Delay Time and Fall Time as Parameters" Annals of the CIRP (v41/1, 1992), pp243-246.

3. V. Garbajs, "Statistical Model for an Adaptive Control of EDMProcess," Annals of the CIRP (v34/1, 1985), pp499-502.

4. C. Cogun, "Computer Aided Evaluation and Control of Electric Discharge Machining by Using Properties of Voltage Pulse Trains," Int $\%$ Journal of Machine Tools and Manufacture (v30, n1, 1990), pp237-247.

5. S.M. Pandit and W.H. Wittig, "A Data-Dependent Systems Approach to Optimal Microcomputer Control Illustrated by EDM," ASME Journal of Engg. for Industry (v106, 1984), ppl37-142.

6. K.P. Rajurkar and W.M. Wang, "Real-Time Stochastic Model and Control of EDM," Annals of the CIRP (v39/1, 1990), pp187-190.

7. K.P. Rajurkar and W.M. Wang, "A New Model Reference Adaptive Control of EDM," Annals of the CIRP (v38/1, 1989), pp 183-186.

8. W.M. Wang and K.P. Rajurkar, "Modeling and Adaptive Control of EDM Systems," Journal of Mfg. Systems (v11, n5, 1992), pp334-345.

9. K.P. Rajurkar and W.M. Wang, "Adaptive Control of WEDM by OnLine Identifying Workpiece Height," Trans. of NAMRI/SME (Vol. XXIl, 1994), pp73-78.

10. K.P. Rajurkar, W.M. Wang, and J.A. McGeugh, "WEDM Identification and Adaptive Control for Variable Height Components." Annals of the CIRP (v43/1, 1994), pp 199-202.

11. A. Moria, Y. Iami, A. Noda, H. Maruyma, and K. Kobayashi, "Fuzzy Controller for EDM," Proc. of 9th Int'1 Symp. for Electromachining, ISEM-9 (1986), pp236-239.

12. Y. Xiong, S. Oi, and S. Mao, "Fuzzy Pattern Recognition and Fuzzy Control in EDM," Proc: of 9th Int'l Symp. for Electromachining, ISEM-9 (1986), pp357-360.

13. W. Dekeyser, R. Snoeys, and M. Jennes, "Expert System for Wire Cutting EDM Based on Pulse Classification and Thermal Modeling," Robotics \& Computer-Integrated Mfg. (v4, n1/2, 1988), pp219-224. 
14. J.Y. Zhu, A.A. Shumsheruddin, and J.G. Bollinger, "Control of Machine Tools Using the Fuzzy Control Technique," Annals of the CIRP (v31/1, 1982), pp347-352.

15. K.K. Moon and K. Kyuil, "Feasibility Study of Fuzzy Control Systems in Machining Processes," Robotics and Computer-Integrated Mfg. (v9, n3, 1992), pp211-217.

16. M. Sugeno, Industrial Application of Fuzzy Control (Amsterdam: North-Holland, 1985).

17. "Method and Device for Controlling a Wire Cut Electric Discharge Machine," US Patent 5393947 (Industrial Technology Research Institute, 1995).

18. Y.S. Liao, Y.Y. Chu, and M.T. Yan, "Study of Wire Breaking Process and Monitoring of WEDM," Int'l Journal of Machine Tools and Manufacture (v37, n4, 1997), pp555-567.

19. M. Mizumoto, "Fuzzy Controls Under Various Fuzzy Reasoning Methods," Information Sciences (v45, 1988), pp 129-151.

\section{Authors' Biographies}

M.T. Yan obtained his BS degree from National Chung-Hsing University in 1987, MS degree from National Taiwan Institute of Technology in 1991, and PhD degree from National Taiwan University in 1995, all in mechanical engineering. He is currently a researcher in the Control Kernel Technology Div., Mechanical Industry Research Laboratories of ITRI, Taiwan. His main responsibility is to develop control technologies for wire cutters.

Y.S. Liao graduated with a BS degree from National Taiwan University in 1973. He obtained his MS and PhD degrees from the University of Wisconsin-Madison in 1976 and 1980, respectively, both in mechanical engineering. In 1981, he joined the Department of Mechanical Engineering at National Taiwan University and is now a professor and director of the machine shop of that department. His major research interest includes machining of difficult-to-cut materials, electrical discharge machining, and machine tool dynamics and control.

\title{
International Conference on Education in Manufacturing
}

\section{"Manufacturing Education for Excellence in the Global Economy" \\ October 14-16, 1998, Town \& Country Hotel, San Diego, California U.S.A.}

\author{
Co-Chairs: \\ M. Eugene Merchant, Institute of Advanced Manufacturing Sciences, Inc. \\ Gustav J. Olling, Chrysler Corporation.
}

This conference is the second major forum convening international leaders, government officials, industry representatives, and others to address key issues and solutions that are redefining education and research in manufacturing. Take advantage of this unique opportunity to focus on industry-driven manufacturing education, innovative curriculum models, international data for benchmarking programs, and worldwide partnerships. In addition to conference sessions, workshops are offered on improving partnerships, teamwork, and managing cross-disciplinary programs. Hands-on demonstrations of leading-edge multimedia curriculum materials and resources are also planned.

Save $\$ 50$ if you register by Tuesday, September 1, 1998. For more information access, the conference home page on the Internet at: http://www.sme.org. To register, contact Customer Service at 1-800-733-4763 (outside the US call 1-313-271-1500, extension 629) or contact the Education Department at education@sme.org with your postal address to receive a printed program. 